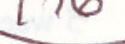

\title{
A Survey of Salmonella Contamination in Modern Broiler Production
}

\author{
F. T. JONES ${ }^{1 *}$, R. C. AXTELL ${ }^{2}$, D. V. RIVES ${ }^{1}$, S. E. SCHEIDELER ${ }^{1}$, \\ F. R. TARVER, JR. ${ }^{3}$, R. L. WALKER', and M. J. WINELAND' \\ 'Department of Poultry Science, ${ }^{2}$ Department of Entomology, \\ ${ }^{3}$ Professor Emeritus Department of Food Science; North Carolina State University, \\ Raleigh, North Carolina 27695, ' California Veterinary Diagnostic Laboratory, School of \\ Veterinary Medicine, University of California. Davis, California 95616.
}

(Received for publication November 8, 1990)

\begin{abstract}
A survey of contamination with Salmonella was done in the breeder/multiplier and broiler houses, feed mills, hatcheries, and processing plants of two integrated broiler firms. Samples of insects and mice were also collected at each location. Sixty percent $(60 \%)$ of the meat and bone meal samples collected at feed mills were contaminated. Salmonella was isolated from $35 \%$ of the mash feed samples tested. The pelleting process reduced Salmonella isolation rates by $82.0 \%$. Data collected from breeder/ multiplier houses suggested that feed was the ultimate source of Salmonella contamination in that environment. Salmonella was found in $9.4 \%$ of the yolk sac samples collected from day-old chicks in hatcheries. Fecal dropping samples collected in broiler houses about one week prior to slaughter were contaminated at a rate of $5.2 \%$. Salmonella was found in $33 \%$ of the samples collected from live haul trucks and $21.4 \%$ of the whole processed broiler carcasses sampled at processing plants. Salmonella typhimurium was the serotype most commonly isolated. The gastrointestinal tract of one of 19 mice sampled was contaminated with Salmonella. Data suggest that insects were primarily mechanical carriers. Results suggest Salmonella contamination in the U.S. broiler production and processing system has changed little since 1969. The data also underline the contention that effective Salmonella control efforts must be comprehensive.
\end{abstract}

In 1985 the National Research Council (23) stated that illnesses caused by Salmonella and Campylobacter jejuni were most commonly traced to poultry products. Two years later, the National Research Council (24) stated: "There is conclusive evidence that microorganisms pathogenic to humans (such as Salmonella and Campylobacter) are present on poultry at the time of slaughter and at retail." Control and eventual elimination of Salmonella from poultry products has been the goal of researchers and the poultry industry for over 25 years $(17,32)$.

A number of surveys have been conducted of Salmonella contamination in various parts of the broiler production system. In the last comprehensive survey of the U.S.

*Author to whom correspondence should be addressed. broiler production system, Morris et al. (22) found that feed samples were most frequently contaminated with Salmonella, but that breeder/multiplier flocks could also pass contamination to their progeny. Dougherty (9) studied Salmonella contamination in broiler flocks and reported that up to $37.5 \%$ of the day-old chicks in his study were contaminated with Salmonella, but the contamination rate decreased to about $5.0 \%$ in broilers just prior to processing. Dougherty (9) also found that the Salmonella serotypes present in feed ingredients were not the same as those in broiler flocks and suggested that contamination in broiler flocks may have originated from either breeder/multiplier flocks or from the hatchery. In a survey of the Australian broiler production system, MacKenzie and Bains (21) found that $82 \%$ of the Salmonella isolated from broiler carcasses could be traced to feed or feed ingredients. However, these researchers failed to examine day-old chicks or breeder hens. Bhatia et al. (3) reported that Salmonella isolation from litter was a reliable indicator of both flock and carcass contamination. Bhatia and McNabb (2) traced Salmonella contamination from the hatchery to the processing plant and found the same Salmonella serotype in fluff and meconium samples collected at the hatchery, in litter samples at the broiler farm, and on carcasses following processing. Soerjadi-Liem and Cumming (33) sampled the ceca of broiler flocks for contamination with Salmonella contamination at the processing plant on a monthly basis for a year and found more contamination in the colder than in the warmer months. These researchers also found that birds raised on old litter were contaminated at much lower rates than were birds raised on new litter. Lahellec and Colin (19) surveyed the French broiler production system and found that Salmonella serotypes originating in the hatchery were less prevalent in the final product than those in the poultry house during the rearing of birds. In another study, Lahellec et al. (20) reported that the Salmonella serotypes isolated on the chicks' first day in the poultry house were most often present in the final product when broilers were raised on new litter. Goren et al. (13) surveyed the broiler production system in The Netherlands and found a positive 
correlation between Salmonella isolation rates from litter at 5 weeks of age and isolation rates from ceca at processing. Preventing exposure of live birds to Salmonella under the current U.S. broiler production has been reported to be difficult, if not impossible (38), since Salmonella can be isolated from virtually anywhere and most birds contaminated with Salmonella show no symptoms of infection (18). Salmonella free poultry have been successfully raised only under very controlled conditions (29) and the elimination of Salmonella from poultry in large scale production has been judged to be uneconomical (18). A comprehensive approach would appear to be required both to surveys of contamination and to control of Salmonella in broilers. Yet Morris et al. (22) reported the last comprehensive survey of the U.S. broiler production and processing system in 1969. Therefore, this study was undertaken to comprehensively examine Salmonella contamination in the U.S. broiler production and processing system.

\section{MATERIALS AND METHODS}

\section{Sampling methods}

The two integrated broiler firms which cooperated with this study followed typical industry practices, but neither firm had an active microbial control program. Samples were collected from each company on three separate days two weeks apart. Samples were collected from two different breeder/multiplier houses, two different broiler houses, the feed mill, the hatchery, and the processing plant on each sampling day. Insects and mice were trapped at each location and transported to the laboratory for analysis. To ensure that any contamination detected was internal, the external surfaces of insects was sanitized. Insects were either rinsed three times in sterile distilled water or sanitized for $30 \mathrm{~s}$ with a $20 \mathrm{ppm}$ chlorine solution and rinsed three times in sterile distilled water before being placed into tryptic soy broth (TSB, Difco, Detroit, MI) for analysis. Captured mice were killed using carbon dioxide, wet thoroughly with $95 \%$ ethanol, aseptically opened with sterile scissors, and the entire gastrointestinal tract was aseptically removed. The tract was then cut into 6 to 10 pieces before being placed in TSB for incubation.

In breeder/multiplier houses, subsamples of feed, floor and nest litter were collected from five locations within each house using sterile tablespoons. Composite samples were made by combining subsamples and mixing thoroughly in a sterile, aluminum roasting pan. About $25 \mathrm{~g}$ of the material was then transferred directly to TSB for incubation. Eggs were collected by hand and rinses were done using the method of Gentry and Quarles (12).

In broiler houses, samples were collected when birds were 67 weeks of age. Composite samples of feed and litter were collected as in breeder/multiplier houses. Water samples (ca. 5 $\mathrm{ml}$ ) were obtained using a sterile tablespoon from five watering devices into TSB. Live and dead bird rinses were done using the method described by Cox et al. (7). Environmental swabs were collected by wetting a sterile cotton-tipped swab (Fisher Scientific, Pittsburgh, PA) with TSB and rubbing it over an area of about $930 \mathrm{~cm}^{2}$ before returning it to the medium for incubation. A new pair of disposable latex gloves were worn during the collection of environmental swabs.

In feed mills, grab samples of feed ingredients (ca. $500 \mathrm{~g}$ ) were collected at the batch scales, while finished feed samples (ca. $500 \mathrm{~g}$ ) were collected from pellet coolers and during loading of feed delivery trucks. Environmental swabs were collected as described above.

In hatcheries, composite samples of yolk sac material were collected from six day-old chicks. Following cervical dislocation, the abdomen of the chick was thoroughly wetted with $95 \%$ ethanol, the chick was aseptically opened with sterile scissors and a 1-g portion of excised yolk material was placed in TSB for incubation. Yolk sac materials from six chicks were combined to form one composite sample. Samples of Marek's disease vaccine were collected by allowing the vaccinating apparatus to deliver one dose of vaccine directly into media for incubation. Environmental swabs were collected from hatchers and chick boxes as described except sterile cotton-tipped swabs were used to rub about $6.5 \mathrm{~cm}^{2}$ of surface area.

At processing plants, three subsamples of debris were collected from shipment coops using sterile tablespoons. Subsamples were combined to form composite samples, of which three to seven were collected on each sampling day. Four to six composite cloacal swab samples were collected after birds were hung on the processing line just prior to kill. Each composite represented cloacal swabs collected from five different birds. Carcass rinse samples were collected on individual birds at the immersion chiller exit and just prior to packaging. Rinses were done using the method described by Cox et al. (7).

\section{Laboratory procedures}

All media were obtained from Difco Laboratories, Inc., Detroit, MI. Samples of approximately $25 \mathrm{~g}$ were transferred directly into $225 \mathrm{ml}$ of TSB, while smaller samples (ca. $1 \mathrm{~g}$ ) and swab samples were placed in $10 \mathrm{ml}$ TSB. TSB was incubated at $37^{\circ} \mathrm{C}$ for $24 \mathrm{~h}$ and $1 \mathrm{ml}$ of TSB was aseptically transferred to both tetrathionate broth (TB) and selenite cystine broth (SCB). TB was incubated at $42^{\circ} \mathrm{C}$ for $24 \mathrm{~h}$, while SCB was incubated at $37^{\circ} \mathrm{C}$ for $24 \mathrm{~h}$. One half $\mathrm{ml}$ of both TB and SCB were transferred to $\mathrm{M}$ broth (MB) which was incubated at $42^{\circ} \mathrm{C}$ for $6 \mathrm{~h}$. MB was then tested for the presence of Salmonella using the Bio-EnzaBead ${ }^{\mathrm{TM}}$ system (Organon Teknika, Durham, NC) as described by Flowers et al. (10). One loop ( $3 \mathrm{~mm}$ ) of MB, TB and SCB from positive samples was streaked on MacConkey agar, hektoen enteric agar and bismuth sulfite agar. Suspect colonies were picked to tubes containing $2 \mathrm{ml}$ of TSB, grown for 18 to $24 \mathrm{~h}$ at $37^{\circ} \mathrm{C}$ and tested for ability to utilize urea using methods described by Poelma et al. (26). Urea negative cultures were identified biochemically as Salmonella using Micro-Id system (Organon-Teknika). Isolates identified as Salmonella were sent to National Veterinary Services Laboratory, Ames, IA for serotyping.

\section{RESULTS}

Salmonella were most frequently found in samples collected from feed mills (FM), followed by those collected at processing plants (PP), from insects and breeder/multiplier houses (B/MH) (Table 1). Samples collected at hatcheries $(\mathrm{H})$, from mice and at broiler houses $(\mathrm{BH})$ were less frequently contaminated.

TABLE 1. Salmonella in broiler production and processing.

\begin{tabular}{lllr}
\hline \multirow{2}{*}{ Sampling location } & \multirow{2}{*}{ No. samples } & nositive samples \\
& & $\%$ \\
\hline Feed Mills & 212 & 44 & 20.8 \\
Breeder/Multiplier houses & 177 & 23 & 13.0 \\
Hatcheries & 140 & 10 & 7.1 \\
Broiler houses & 267 & 12 & 4.5 \\
Processing plants & 137 & 22 & 16.1 \\
Insects & 100 & 13 & 13.0 \\
Mice & 19 & 1 & 5.3 \\
\hline
\end{tabular}

In FM samples, meat and bone meal, poultry meal, fish meal, and other ingredients were contaminated with Salmonella at rates 
of $60 \%, 40 \%, 33.3 \%$, and $20.8 \%$, respectively (Table 2). Salmonella was not isolated from environmental swabs but was found in one of eight $(12.5 \%)$ dust samples collected. Salmonella was isolated from mash feeds at a rate of $35 \%$ and from pelleted feeds at a rate of $6.3 \%$. A comparison of the isolation rates obtained from mash feeds with those from pelleted feeds, indicated that the pelleting process reduced Salmonella isolation rates by $82 \%$. Salmonella typhimurium was the predominant serotype isolated from pelleted feeds. However, a wide variety of Salmonella serotypes was also found in feed and feed ingredient samples (Table 8).

Salmonella isolation rates were similar for feed, nest litter, and nest egg rinse samples collected from B/MH (Table 3). Since breeder birds consumed mash feed and Salmonella contamination rates for mash feed were higher than those of pelleted feeds sampled at the FM (Table 2), these data suggest that feed was the source of Salmonella contamination in B/MH. The fact that $S$. typhimurium was serotype most commonly isolated from feed, nest litter, and nest egg rinse samples also supports feed as the contamination source. Floor egg rinse and floor litter samples (Table 3) also had similar contamination rates, but $S$. typhimurium was the most common serotype on floor eggs, while $S$. indiana was most common in floor litter.

TABLE 2. Salmonella in feed mills.

\begin{tabular}{llrr}
\hline & & \multicolumn{2}{c}{ Positive samples } \\
Sample type & No. samples & No. & \multicolumn{1}{c}{$\%$} \\
\hline Dust & 8 & 1 & 12.5 \\
Environmental swabs & 18 & 0 & 0.0 \\
Fish meal & 18 & 6 & 33.3 \\
Meat \& Bone meal & 15 & 9 & 60.0 \\
Poultry meal & 10 & 4 & 40.0 \\
Other ingredients & 24 & 5 & 20.8 \\
Mash feeds & 40 & 14 & 35.0 \\
Pelleted feeds & 79 & 5 & 6.3 \\
All samples & 212 & 44 & 20.8 \\
\hline
\end{tabular}

TABLE 3. Salmonella in breeder/multiplier houses.

\begin{tabular}{lccc}
\hline \multirow{2}{*}{ Sample type } & No. samples & \multicolumn{2}{c}{ Positive samples } \\
\hline Cecal droppings & 65 & 8 & 12.3 \\
Feed & 14 & 2 & 14.3 \\
Floor egg rinse & 12 & 1 & 8.3 \\
Floor litter & 28 & 3 & 10.7 \\
Nest egg rinse & 30 & 5 & 16.7 \\
Nest litter & 28 & 4 & 14.3 \\
All samples & 177 & 23 & 13.0 \\
\hline
\end{tabular}

Salmonella was found in the yolk sac of $9.4 \%$ of the chicks sampled in $\mathrm{H}$ (Table 4), with typhimurium being the most common serotype. Salmonella heidelberg was found in one of the 14 swab samples $(7.1 \%)$ collected from hatchers, but no Salmonella were isolated from dead embryos, chick boxes, or vaccinator samples.

Feed, water, and litter samples collected in $\mathrm{BH}$ were negative for Salmonella (Table 5). Contamination rates of $14.3 \%, 7.1 \%$, and $5.2 \%$ were obtained from dead bird, live bird, and fecal dropping samples, respectively. One of the 42 environmental swabs was positive for Salmonella. Samples from $\mathrm{BH}$ were collected from birds which were processed less than a week after samples were collected. The serotype most commonly isolated from live birds, dead birds, fecal droppings and environmental swabs was S. typhimurium. The failure to isolate Salmonella from feed samples collected on the broiler farm suggests that broilers
TABLE 4. Salmonella in hatcheries.

\begin{tabular}{lccc}
\hline & & \multicolumn{2}{l}{ Positive samples } \\
Sample type & No. samples & No. & $\%$ \\
\hline Chicks (yolk sac) & 96 & 9 & 9.4 \\
Chick boxes & 7 & 0 & 0.0 \\
Dead embryos & 9 & 0 & 0.0 \\
Hatcher & 14 & 1 & 7.1 \\
Vaccinator & 14 & 0 & 0.0 \\
All samples & 140 & 10 & 7.1 \\
\hline
\end{tabular}

TABLE 5. Salmonella in broiler houses.

\begin{tabular}{lccc}
\hline & & \multicolumn{2}{c}{ Positive samples } \\
Sample type & No. samples & No. & $\%$ \\
\hline Dead bird rinse & 14 & 2 & 14.3 \\
Environmental swabs & 42 & 1 & 2.4 \\
Fecal droppings & 155 & 8 & 5.2 \\
Feed & 14 & 0 & 0.0 \\
Litter & 14 & 0 & 0.0 \\
Live bird rinse & 14 & 1 & 7.2 \\
Water & 14 & 0 & 0.0 \\
All samples & 267 & 12 & 4.5 \\
\hline
\end{tabular}

TABLE 6. Salmonella in processing plants.

\begin{tabular}{lccc}
\hline & & \multicolumn{2}{c}{ Positive samples } \\
Sample type & No. samples & No. & $\%$ \\
\hline Carcasses at chiller exit & 56 & 6 & 10.7 \\
Carcasses at packaging & 14 & 3 & 21.4 \\
Cloacal swabs & 28 & 0 & 0.0 \\
Live haul trucks & 39 & 13 & 33.3 \\
All samples & 137 & 22 & 16.1 \\
\hline
\end{tabular}

were not contaminated directly by feed. However, the predominance of $S$. typhimurium in feed samples collected at the feed mill, and in breeder/multiplier flocks, suggests an indirect contamination route.

Salmonella was found in $33.3 \%$ of the samples collected from live haul trucks at PP, but was not isolated from cloacal swabs collected from birds just prior to kill (Table 6). Whole processed broiler carcasses were contaminated at a rate of $21.4 \%$. Salmonella was found about half as frequently in birds exiting the chiller as in birds at packaging, suggesting that plant workers or equipment cross-contaminated carcasses. A diverse mixture of Salmonella serotypes including $S$. muenster, $S$. typhimurium, $S$. heidelberg, and $S$. hadar was isolated from live haul trucks. A variety of Salmonella serotypes was also isolated from processed broiler carcasses, but $S$. typhimurium was most commonly isolated.

Insect samples listed in Table 7 were collected from $\mathrm{B} / \mathrm{MH}$, $\mathrm{BH}, \mathrm{FM}, \mathrm{H}$, and PP. Unfortunately, few samples were obtained of most insect species. Nonetheless, Salmonella was isolated from Lesser meal worms, American cockroaches, and German cockroaches. However, since Salmonella was isolated over 10 times less frequently from insects disinfected with $20 \mathrm{ppm}$ chlorine than from insects not disinfected, these data suggest that insects were primarily mechanical carriers of Salmonella. A number of Salmonella serotypes were isolated from insects including (in order of isolation): $S$. othmarchen, $S$. orangenberg, $S$. thompson, $S$. heidelberg and $S$. infantis.

$S$. typhimurium was the serotype most commonly isolated from the $\mathrm{B} / \mathrm{MH}, \mathrm{BH}, \mathrm{FM}$, and PP sampled (Table 8). Since 20 of 
TABLE 7. Salmonella in insects.

\begin{tabular}{|c|c|c|c|c|c|c|c|c|c|}
\hline \multirow[t]{2}{*}{ Insects } & \multicolumn{3}{|c|}{ Disinfected } & \multicolumn{3}{|c|}{ Undisinfected } & \multicolumn{3}{|c|}{ Total } \\
\hline & $\begin{array}{l}\text { No. } \\
\text { ples }\end{array}$ & $\begin{array}{l}\text { No. } \\
\text { pos. }\end{array}$ & $\begin{array}{l}\% \\
\text { pos. }\end{array}$ & $\begin{array}{l}\text { No. } \\
\text { samples }\end{array}$ & $\begin{array}{l}\text { No. } \\
\text { pos. }\end{array}$ & $\begin{array}{l}\% \\
\text { pos. }\end{array}$ & $\begin{array}{c}\text { No. } \\
\text { samples }\end{array}$ & $\begin{array}{l}\text { No. } \\
\text { pos. }\end{array}$ & $\begin{array}{l}\% \\
\text { pos. }\end{array}$ \\
\hline \multicolumn{10}{|l|}{ Lesser meal worm } \\
\hline Alphatobius spp. & 44 & 2 & 4.5 & 14 & 6 & 42.9 & 58 & 8 & 13.8 \\
\hline \multicolumn{10}{|l|}{ American cockroach } \\
\hline Periplaneta americana & 7 & 0 & 0.0 & 7 & 4 & 57.1 & 14 & 4 & 28.6 \\
\hline \multicolumn{10}{|l|}{ German cockroach } \\
\hline Blatella germanica & 4 & 0 & 0.0 & 4 & 1 & 25.0 & 8 & 1 & 12.5 \\
\hline \multicolumn{10}{|l|}{ Caracinops beetle } \\
\hline Carcinops pumuilo & 4 & 0 & 0.0 & 4 & 0 & 0.0 & 8 & 0 & 0.0 \\
\hline \multicolumn{10}{|l|}{ Blow fly } \\
\hline$\underline{\text { Phaenicin sericata }}$ & 2 & 0 & 0.0 & 2 & 0 & 0.0 & 4 & 0 & 0.0 \\
\hline \multicolumn{10}{|l|}{ Darkling beetlel } \\
\hline Alphatobius diaperinuns & 4 & 0 & 0.0 & 0 & 0 & 0.0 & 4 & 0 & 0.0 \\
\hline \multicolumn{10}{|c|}{ House fly } \\
\hline Musca domestica & 2 & 0 & 0.0 & 0 & 0 & 0.0 & 2 & 0 & 0.0 \\
\hline \multicolumn{10}{|l|}{ Confused flour beetle } \\
\hline$\underline{\text { Tribdium confusum }}$ & 2 & 0 & 0.0 & 0 & 0 & 0.0 & 2 & 0 & 0.0 \\
\hline All samples & 69 & 2 & 2.9 & 31 & 11 & 35.5 & 100 & 13 & 13.0 \\
\hline
\end{tabular}

TABLE 8. Salmonella serotypes isolated from the broiler production and processing system.

\begin{tabular}{|c|c|c|c|c|c|c|}
\hline Serotype & Breeder House & $\begin{array}{r}\text { Broiler House } \\
(\mathrm{N}\end{array}$ & $\begin{array}{l}\text { Feed mill } \\
\text { isolates) }\end{array}$ & Hatchery & Processing & Totals \\
\hline Adelaide & & & 13 & & & 13 \\
\hline Agona & & & 2 & & & 2 \\
\hline Anatum & 7 & 5 & & & & 12 \\
\hline Binza & & & 3 & & & 3 \\
\hline Broughton & & & 5 & & & 5 \\
\hline Cerro & & & 3 & & & 3 \\
\hline Hadar & & 3 & 1 & & 7 & 11 \\
\hline Havana & & & 4 & & & 4 \\
\hline Heidelberg & 6 & 6 & 3 & 6 & 6 & 27 \\
\hline Indiana & 9 & & 2 & & & 11 \\
\hline Infantis & & & 3 & & & 3 \\
\hline Lexington & & & 1 & & & 1 \\
\hline Mbandaka & & & 4 & & & 4 \\
\hline Muenster & & & & & 6 & 6 \\
\hline Neumuenster & & & 3 & & & 3 \\
\hline Newington & & & 4 & & & 4 \\
\hline Ohio & & & 1 & & & 1 \\
\hline Orangienburg & & & 1 & & & 1 \\
\hline Othmarchen & & & 2 & 5 & & 7 \\
\hline Thompson & & & 3 & & & 3 \\
\hline Typhimurium & 12 & 10 & 30 & 6 & 10 & 68 \\
\hline Untypable & 7 & & & 4 & & 11 \\
\hline Worthington & & & 3 & & 5 & 8 \\
\hline Total & 41 & 24 & 91 & 21 & 34 & 211 \\
\hline
\end{tabular}

the 23 serotypes isolated were found in feed, these data suggest that feed was a great repository of serotypes. However, these data also suggest that effective Salmonella control efforts must be comprehensive. Nonetheless, since $S$. heildelberg and $S$. typhimurium were the only two serotypes isolated from $\mathrm{B} / \mathrm{MH}$, $\mathrm{BH}, \mathrm{FM}, \mathrm{H}$, and PP, perhaps only a limited number of serotypes were capable of transmission from one location to another.

\section{DISCUSSION}

The following percentages of samples positive for Salmonella in this study (Table 1) and the last comprehensive survey (22) are as follows: FM samples, 20.8 vs. $21.5 \%$; B/MH samples, 13.0 vs. $11.8 \%$; $\mathrm{H}$ samples, 7.1 vs. $1.9 \%$; BH samples, 4.5 vs. $7.8 \%$; and PP samples, 16.1 vs. 
$12.7 \%$. These data suggest that little has changed since the last comprehensive survey with respect to Salmonella contamination in the U.S. broiler production and processing system.

Salmonella was most frequently isolated from feed and feed ingredients (Table 1). While this finding confirms the findings of other researchers $(21,22)$, the Salmonella isolation rates from $\mathrm{B} / \mathrm{MH}$ cecal droppings (12.3\%) (Table 3), from day-old broiler chicks (9.4\%) (Table 4), and from live birds at broiler farms $(7.1 \%)$ (Table 5) suggest that the $\mathrm{B} /$ $\mathrm{MH}$ environment was also important in the transmission of contamination to the final product. Furthermore, the variety of serotypes isolated from processed broiler carcasses suggests that the complete elimination of Salmonella from feed would not mean the elimination of this pathogen from the final product. The ubiquitous nature of Salmonella contamination in the broiler production system (38) necessitates a comprehensive approach to control. Nonetheless, a detailed examination of contamination in the various sampling locations would also appear to be necessary.

The Salmonella contamination rate observed in mice $(5.3 \%)$ (Table 1) is similar to that observed by Dack ( 8 ) who found that $1.2 \%$ of the rat and mice excreta samples tested were positive. This result was also not surprising since the most commonly isolated serotype (S. typhimurium) (Table 8) causes disease in mice (36).

The contamination rate we report (Table 2) for meat and bone meal $(60 \%)$ is comparable to that $(67 \%)$ previously reported for animal protein products (30), but is lower than the contamination rate reported by others $(21,22)$ for meat and bone meal ( $87.2 \%$ and $72 \%$, respectively). Estimates of the number of Salmonella organisms found in animal feed ingredients range from 1 to 40 Salmonella organisms/100 grams $(25,35)$. However, Gabis (11) has suggested that rendered animal by-products become contaminated with Salmonella following cooking as a result of microbial growth niches in the postcooking environment. High numbers of many different microorganisms (including Salmonella) may be found in these growth niches. As rendered products are conveyed from the cookers to finished product storage areas, varying amounts of these highly contaminated materials slough off or fall into the cooked product (11). Thus, the number of Salmonella organisms contaminating animal feed ingredients may be highly variable.

Pelleting of feeds has been suggested as a method of decontaminating Salmonella containing feeds (37). However, Blankenship et al. (4) indicated that whether or not the pelleting process eliminates Salmonella from poultry feeds is dependent upon: feed moisture, time and temperature of conditioning, number of Salmonella present, efficiency of heat and moisture transfer in feeds and the thermal resistance of the Salmonella strain involved. Our data (Table 2) and those of Shrimpton (30) indicate that pelleting reduces Salmonella isolation rates in feeds by $82.0 \%$ and $81.1 \%$, respectively. Thus, the pelleting process is effective at reducing Salmonella isolations from feeds but does not completely eliminate the organism from feeds. It should also be noted that one Salmonella organism in 10 $\mathrm{g}$ of feed has been reported capable of causing colonization in chicks of $4 \mathrm{~d}$ of age or less (34).

Snoeyenbos (3I) found that after $30 \mathrm{~d}$ of egg production in B/MH, Salmonella were more frequently isolated from nest than from floor litter. Our data substantiate these findings (Table 3 ) and suggest that the contamination of nest litter may have been an important vehicle in the transmission of contamination from feed to the final product. However, Humphrey and Lanning (16) found that Salmonella isolation rates from breeder/multiplier feed were reduced by the addition of $0.5 \%$ formic acid to feed, but isolation rates obtained from broiler ceca collected at the plant remained the same. These researchers suggested that measures to reduce contamination in broiler houses would be required to reduce Salmonella isolation rates in broiler ceca at the processing plant.

The contamination rate $(9.4 \%)$ we report for yolk sac contamination in the hatchery (Table 4 ) is slightly higher than the $6.6 \%$ and $5.0 \%$ reported by Bhatia et al. (3) and Lahellic and Colin (19), respectively. The results obtained from hatchers are comparable to those of Lahellic and Colon (19) (6.3\%), but both isolation rates are considerably lower than those of Cox and Bailey (6) (88\%). However, these data, in reality, are not comparable, since Cox and Bailey collected samples from chick belts, egg fragments, and paper pads, while samples were collected from hatchers during the other two studies.

The Salmonella isolation rate we report from fecal droppings $(5.2 \%)$ in $\mathrm{BH}$ (Table 5) is higher than that reported from a study (9) conducted on old litter $(2.5 \%)$, but it is lower than those reported by two other studies $(19,20)$ conducted on new litter $(13.2 \%$ and $22.9 \%$, respectively). Since Salmonella are isolated less frequently from flocks reared on old litter than those reared on new litter (33), perhaps litter type can account for the discrepancies in these data.

The isolation rate we report from live haul trucks $(33.3 \%)$ (Table 6) is similar to that reported by Goren et al. (13) $(29.6 \%)$, but both rates are lower than those reported by Rigby et al. (28) (86.6\%). Goren et al. (13) found a high degree of similarity between the Salmonella serotypes isolated from transportation crates and those isolated from the skin of processed broilers.

The failure to isolate Salmonella from cloacal swabs is analogous to the data reported by Rigby and Pettit (27) and Bailey and Cox (1), both of whom concluded that more recoveries were made from samples taken from the ceca than from cloacal swabs. Since Bailey and Cox $(l)$ have shown that cloacal swabs do not detect $<10^{4}$ organisms, these results suggest that most birds were carrying $<10^{4}$ Salmonella as they entered the plant. These data are consistent with data reported by Campbell et al. (5), who found that $93.5 \%$ of the carcasses sampled at final rinse contained 30 or fewer Salmonella organisms per carcass

The $21 \%$ contamination rate we reported for whole processed broiler carcasses (Table 6) is lower than the $37 \%$ reported by Green et al. (14). Since broiler flocks sampled during the colder months have higher rates of Salmonella contamination than flocks sampled during the warmer months (33), seasonal effects may account for these differences. Our data were collected during the warmer months, 
while Green et al. (14) do not mention season of the year. Greenberg (15) found a high percentage of contamination in slaughterhouse flies and observed that Salmonella persisted from the maggot to the adult stage. While Salmonella was isolated from lesser meal worms, American cockroaches, and German cockroaches (Table 7), our data suggest that Salmonella was not maintained internally in the insects sampled. Since Greenberg (15) has shown that Salmonella can be recovered from tagged flies at distances up to 3 miles from their point of origin, the question of whether contamination of insects is internal or external may be a moot point. Nonetheless, our data suggest that insects simply mechanically transport Salmonella organisms. While the data collected certainly do not discount the role of insects in the transmission of Salmonella, the data do suggest that when the primary sources of Salmonella are eliminated, the organism will also disappear from the insect population.

In summary, the data reported here are similar to those reported over 20 years ago (22). Salmonella was most frequently isolated from feeds and feed ingredients (Table 1). Yet the similarity in contamination rates observed in cecal droppings collected from breeder/multiplier houses (Table 3), day-old chicks (Table 4), and live birds in broiler houses (Table 5) suggests that the breeder/multiplier house environment is an important vehicle for the transmission of contamination from feed to the final product. These data underline the need for a comprehensive approach in the control of Salmonella contamination in the broiler production and processing system.

\section{ACKNOWLEDGMENTS}

The technical assistance of Timothy Hurley and George Gartrell is greatly appreciated. This work was supported by Southeastern Poultry and Egg Association Grant \#M2. The authors gratefully acknowledge the support.

\section{REFERENCES}

1. Bailey, J. S., and N. A. Cox. 1989. Effect of age of chick and challenge dose level on Salmonella typhimurium colonization of broilers. Poultry Sci. 68 (suppl. 1):168.

2. Bahatia, T. R. S., and G. D. McNabb. 1980. Dissemination of Salmonella in broiler-chicken operations. Avian Dis. 24:616-624.

3. Bahatia, T. R. S., G. D. McNabb, H. Wyman, and G. P. S. Nayar 1979. Salmonella isolation from litter as an indicator of flock infection and carcass contamination. Avian Dis. 23:838-847.

4. Blankenship, L. C., D. A. Shackelford, N. A. Cox, D. Burdick, J. S. Bailey, and J. E. Thomson. 1984. Survival of salmonellae as a function of poultry feed processing conditions. pp. 211-220 In G. H. Snoeyenbos, (ed), Proc. Int. Sym. Salmonella. American Association of Avian Pathology, Kennett Square, PA.

5. Campbell, D. F., R. W. Johnston, G. S. Campbell, D. McClain, and J. F. Macaluso. 1983. The microbiology of raw, eviscerated chickens: A ten year comparison. Poultry Sci. 62:437-444.

6. Cox, N. A., and J. S. Bailey. 1989. The role of the hatchery and hatchery environment in the colonization of baby chicks with salmonellae. Poultry Sci. 68 (suppl. 1):178.

7. Cox, N. A.. J. E. Thompson, and J. S. Bailey. 1983. Procedure for isolation and identification of Salmonella from poultry carcasses. USDA ARS Agric. Handbook No. 603.

8. Dack, G. M. 1949. Salmonella. pp 119-145. In G. M. Dack (ed.), Food poisoning. University of Chicago Press, Chicago, IL.

9. Dougherty, T. J. 1976. A study of Salmonella contamination in broiler flocks. Poultry Sci. 55:1811-1815.

10. Flowers, R. S., M. J. Klatt, B. J. Robison, J. A. Mattingly, D. A.
Gabis, and J. H. Silliker. 1987. Enzyme immunoassay for detection of Salmonella in low-moisture foods:Collaborative study. J. Assoc. Off. Anal. Chem. 70:530-535.

11. Gabis, D. A. 1990. Environmental factors affecting enteropathogens in feed and feed mills. Proc. 25th Nat. Meet. on Poultry Health and Condem. pp. 42-46.

12. Gentry, R. F., and C. L. Quarles. 1972. The measurement of bacterial contamination on egg shells. Poultry Sci. 51:930-933.

13. Goren, E., W. A. de Jong, P. Doomenbal, N. M. Bolder, R. W. A. W. Mulder, and A. Jansen. 1988. Reduction of Salmonella infection of broilers by spray application of intestinal microflora: a longitudinal study. Vet. Quart. 10(4):249-255.

14. Green, S. S., A. B. Moran, R. W. Johnston, P. Uhler, and J. Chiu 1982. The incidence of Salmonella species and serotypes in young whole chicken carcasses in 1979 as compared with 1967. Poultry Sci. 61:288-293.

15. Greenberg, B. 1964. Experimental transmission of Salmonella typhimurium by houseflies to man. Am. J. Hyg. 80:149-156.

16. Humphrey, T. J., and D. G. Lanning. 1988. The vertical transmission of salmonellas and formic acid treatment of chicken feed. Epidem. Inf . 100: 43-49.

17. Kampelmacher, E. H. 1984. Present and future problems in Salmonella control. pp 297-303. In G. H. Snoeyenbos (ed.), Proc. Int. Sym. Salmonella. American Association of Avian Pathology, Kennett Square, PA.

18. Kampelmacher, E. H. 1987. Poultry disease and public health. Br. Poultry Sci. 28:3-13.

19. Lahellec, C., and P. Colin. 1985. Relationship between serotypes of salmonellae from hatcheries and rearing farms and those from processed poultry carcasses. Br. Poultry Sci. 26: 179-186.

20. Lahellec, C., P. Colin, G. Bennejean, P. Paquin, A. Guillerm, and J. C. Debois. 1986. Influence of resident Salmonella on contamination of broiler flocks. Poultry Sci. 65:2034-2039.

21. MacKenzie , M. A., and B. S . Bains . 1976. Dissemination of Salmonella serotypes from raw feed ingredients to chicken carcasses. Poultry Sci. 55:957-960.

22. Morris, G. K., B. L. McMurray, M. M. Galton, and J. G. Wells. 1969. A study of the dissemination of salmonellosis in a commercial broiler chicken operation. Am. J. Vet. Res. 30: 1413-1421.

23. National Research Council. 1985. Meat and poultry inspection: The scientific basis of the nation's program. Report of the Committee on the Scientific Basis of the Nation's Meat and Poultry Inspection Program, Food and Nutrition Board. National Academy Press, Washington, DC. 209 pp.

24. National Research Council. 1987. Poultry Inspection: The basis for a risk-assessment approach. Report of the Committee on the Scientific Basis of the Nation's Meat and Poultry Inspection Program, Food and Nutrition Board. National Academy Press, Washington, D. C. 167 pp.

25. Patterson, J. T. 1971. Salmonellae in animal feeding stuffs. Rec. Agric. Res. 20:27-33.

26. Poelma, P. L., W. H. Andrews, and J. H. Silliker. 1984. Salmonella. pp. 286-326. In M. Speck (ed.), Compendium of methods for the microbiological examination of foods. 2nd ed. American Public Health Association, Washington, DC.

27. Rigby, C. E., and J. R. Pettit. 1979. Some factors affecting Salmonella typhimurium infection and shedding in chickens raised on litter. Avian Dis. 23:442-455.

28. Rigby, C. E., J. R. Pettit, M. F. Baker, A. H. Bentley, M. O. Salomons, and H. Loir. 1980. Flock infection and transport as sources of salmonellae in broiler chickens and carcasses. Can. J. Comp. Med. 44:328-337.

29. Shapcott, R. C. 1984. Practical aspects of Salmonella control: Progress report on a programme in a large broiler integration. pp 109-114. In G. H. Snoeyenbos (ed.), Proc. Int. Sym. Salmonella. American Association Avian Pathology, Kennett Square, PA.

30. Shrimpton, D. H. 1989. The Salmonella problem of Britain. Milling Flour and Feed, January. pp. 16-17.

31. Snoeyenbos, G. H. 1971. An approach to maintaining Salmonellafree chickens. Avian Dis. 15:28-31.

32. Snoeyenbos, G. H. 1984. Conclusions and recommendations. pp iv. In Snoeyenbos, G. H. (ed.), Proc. Internat. Sym. Salmonella. American Association Avian Pathology, Kennett Square, PA.

33. Soerjadi-Liem, A. S., and R. B. Cumming. 1984. Studies on the incidence of Salmonella carriers in broiler flocks entering a poultry 
processing plant in Australia. Poultry Sci. 63:892-895.

34. Stuart, J. C. 1984. Agricultural Group Symposium Prospects for control of Salmonella in the poultry industry: The introduction of Salmonella into poultry flocks. J. Sci. Food Agric. 35:632-633.

35. Stott, J. A., J. E. Hodson, and J. E. Chaney. 1975. Incidence of salmonellae in animal feed and the effect of pelleting on content of Enterobacteriaceae. J. Appl. Bact. 39:41-46.
36. Taylor, J. 1968. Salmonella in wild animals. Symp. Zool. Soc. (London) 24:51-73.

37. Vanderwal, P. 1979. Salmonella control of feedstuffs by pelleting or acid treatment. Worlds Poultry Sci. J. 30:70-79.

38. Williams, J. E. 1978. Paratyphoid infections. pp 117-168. In M. S. Hofstad (ed.), Diseases of poultry, 7th ed. Iowa State University Press, Ames. 